\title{
Rapid Watershed Assessment Tools Based on High-Resolution Terrain Data
} US Army Corps of Engineers ${ }_{\circledast}$

\author{
by Christopher P. Haring, Charles $\boldsymbol{H}$. Theiling, \\ and Michael P. Dougherty
}

PURPOSE: The goal of this project was to develop rapid watershed assessment methods to estimate channel stability and sediment transport potential using high resolution terrain data (Light Detection and Ranging-LiDAR) to support US Army Corps of Engineers (USACE) watershed planning. This project developed a suite of tools based on advanced remote sensing technologies (LiDAR) that use off-the-shelf, high-resolution terrain data to rapidly assess watershed condition at the channel, floodplain, valley, and watershed scales. The widespread availability of high-resolution terrain data provides an opportunity to assess watershed conditions in great detail over large spatial extents. Automated geomorphometric tools for extracting key floodplain, valley, and watershed scale metrics are widely developed and available. However, existing toolsets have yet to automate and identify many of the well-established fluvial geomorphological metrics and related empirical relationships at the channel scale. The metrics include width-to-depth and entrenchment ratios, sinuosity, meander wavelength, belt width, and others. For this project, a channel assessment method was developed using a new LiDARHydraulic Geometry Relationships (HGR)-based approach for developing regional curves (Haring et al. 2019). Regional curves relate bankfull channel dimensions and discharge to watershed drainage area and are the basis for analyzing and defining channel metrics at large spatial scales within a watershed for this rapid watershed assessment method. If regional or LiDAR-HGR curves are unavailable for a study area, additional channel assessment methods are in development that use existing hydraulic model depth grids and existing channel surveys for analyzing and defining channel metrics.

The goals and objectives of this project are the following:

\section{Goals}

- Provide a rapid watershed assessment method for USACE Planning that identifies high priority restoration and stabilization reaches.

- Develop a USACE Ecological Planning model based on rapid watershed assessment metrics to define restoration and mitigation benefits.

\section{Approach}

- Develop a suite of planning analysis tools to rapidly assess and identify sediment sources, pathways, and sinks for watershed analysis.

- Use existing geomorphic principles to develop metrics for analyzing LiDAR-derived channel, floodplain, valley, and watershed characteristics.

- Develop an approach to relate channel, floodplain, valley, and watershed characteristics to Ecosystem Restoration (ER) habitat evaluation and benefits. 
This project developed a new toolbox for extracting many common channel, floodplain, valley, and watershed geomorphology metrics. The tools apply to common watershed assessment tasks by developing repeatable data analysis and processing workflows. The study developed and applied these workflows using several test watersheds located throughout the country to determine the applicability to a wide range of hydro-physiographic conditions and input data quality.

The rapid watershed assessment approach was developed to better quantify the benefits of streambank stabilization to protect downstream habitats in the Illinois River impacted by excessive sedimentation. The method allows quantification of the potential stream stabilization requirements in a watershed by mapping fluvial geomorphic channel metrics. The various channel metrics map stream reaches by relative channel stability that is based on high, medium, and low erosion potential for the entire watershed as support to watershed planners. The approach also supports ER habitat evaluations that demonstrate links between fisheries data and high-resolution terrain-derived stream channel characteristics and the quality of aquatic habitat. This framework will use geomorphic channel characteristics as predictor variables of aquatic health measured by fish community metrics. Success with linking ecological indicators to a rapid watershed assessment package will provide a powerful remote sensing RS tool to estimate fisheries potential and test alternative management plans.

In addition, tools created for watershed assessments will support project reconnaissance, regulatory permitting, design, and adaptive management phases with increased spatial coverage and accuracy of geomorphic channel, floodplain, and watershed data. The assessment approach will provide more advanced design information to feasibility alternative evaluation and costbenefit analysis studies. Maps and data summaries will support USACE engagements and communication of watershed plans across the spectrum of lay and technical audiences.

STUDY NEED: The Illinois River Basin Restoration (IRBR) Program (WRDA 2007, Section 519 (b) and (c)) established the authority to implement watershed restoration studies to reduce sediment transport to Illinois River backwaters, side channels, and wetlands. Early project planning revealed differences in the broad scope of the watershed plan under one policy guidance (USACE watershed policy, EC1105-2-411) and project implementation under a different guidance (USACE 2000). Watershed assessment "may mean including downstream areas that are otherwise technically not in the local watershed or perhaps including a much broader, more regional watershed to adequately capture the full ranges of influence..." (USACE watershed policy, EC1105-2-411). Planning at the project level may consider "...resources that would be directly, indirectly, or cumulatively affected by alternative plans . . often called the affected area" (USACE 2000). Consequently, it was discovered during early IRBR project planning that USACE methods for stream restoration and ecological benefit analysis were insufficient to document off-site sediment reduction benefits provided by stream stabilization in the watershed. In addition, USACE environmental project cost-benefit analysis (USACE 2000) requires measurable improvement in local habitat conditions (i.e., Habitat Units) that may not be substantial in stream stabilization projects because the projects do not typically capture ecological improvement as much as they stabilize existing conditions to reduce future or off-site impacts.

USACE project planning also includes a host of real estate implications concerning land ownership that precludes taking benefits outside of the project area in federal ownership or easement. As a result, stream restorations evaluate habitat benefits over small stream reaches or 
project areas, rather than over decades of sediment transport reduction benefits to the downstream reaches. With hundreds of potential small watershed projects in the Illinois Basin alone (or any USACE watershed study), there is a need to rapidly define sediment management needs with high resolution over large areas. The USACE emphasis on habitat outcomes requires better capacity to evaluate stream habitat over large spatial scales, so there is also a direct need for a planning tool to that provides high-resolution stream habitat indicators.

CONCEPTUAL FRAMEWORK: A landscape approach was used for this study to define an analytical hierarchy of channel, floodplain, valley, and watershed metrics (Figure 1). The information at each level or in various combinations can be used to classify stream condition for watershed assessments. Floodplain, valley, and watershed metrics define the source of overland flow and the external supply of sediment to streams. Channels and floodplains can be sediment sources, pathways, or sinks depending on local physical conditions that can be characterized as Functional Process Zones (FPZ). Thorp et al. (2006) defined FPZs in River Ecosystem Synthesis, which conceptualized the physical-ecological relationships inherent in watersheds, streams, and rivers as catchments driven by climate and geology. The FPZs are shaped as "linked, discontinuous hierarchies of patch dynamics" formed by physicochemical characteristics that affect ecosystem structure and function.

Recent USACE watershed-scale planning initiatives emphasize integration of landscape ecology principles. Hierarchical landscape principles support science, planning, design, implementation, and monitoring of watershed plans by identifying the function and connectivity of habitat patches relevant to natural resource managers and the public. Williams et al. (2013) reported a wide range of geomorphic watershed characteristics to consider, so this study adopted the spatial hydro-geomorphic variables recommended for US databases applicable across the USACE areas of responsibility as a first-level evaluation.

As an example, by evaluating channel slope and width-to-depth ratios, the RS analysis tools can provide insight on distribution of stream power and sediment transport potential within the watershed stream network. These relationships are mapped at the channel, floodplain, valley, or watershed scale, and potential locations of sources, pathways, and sinks can be identified. In combination with additional variables, they directly influence floodplain and watershed characteristics. The development of RS tools that measure channel HGRs in combination with existing landscape ecological principles (Thorp et al. (2006); Williams et al. (2013) provides tools to rapidly assess watersheds. 


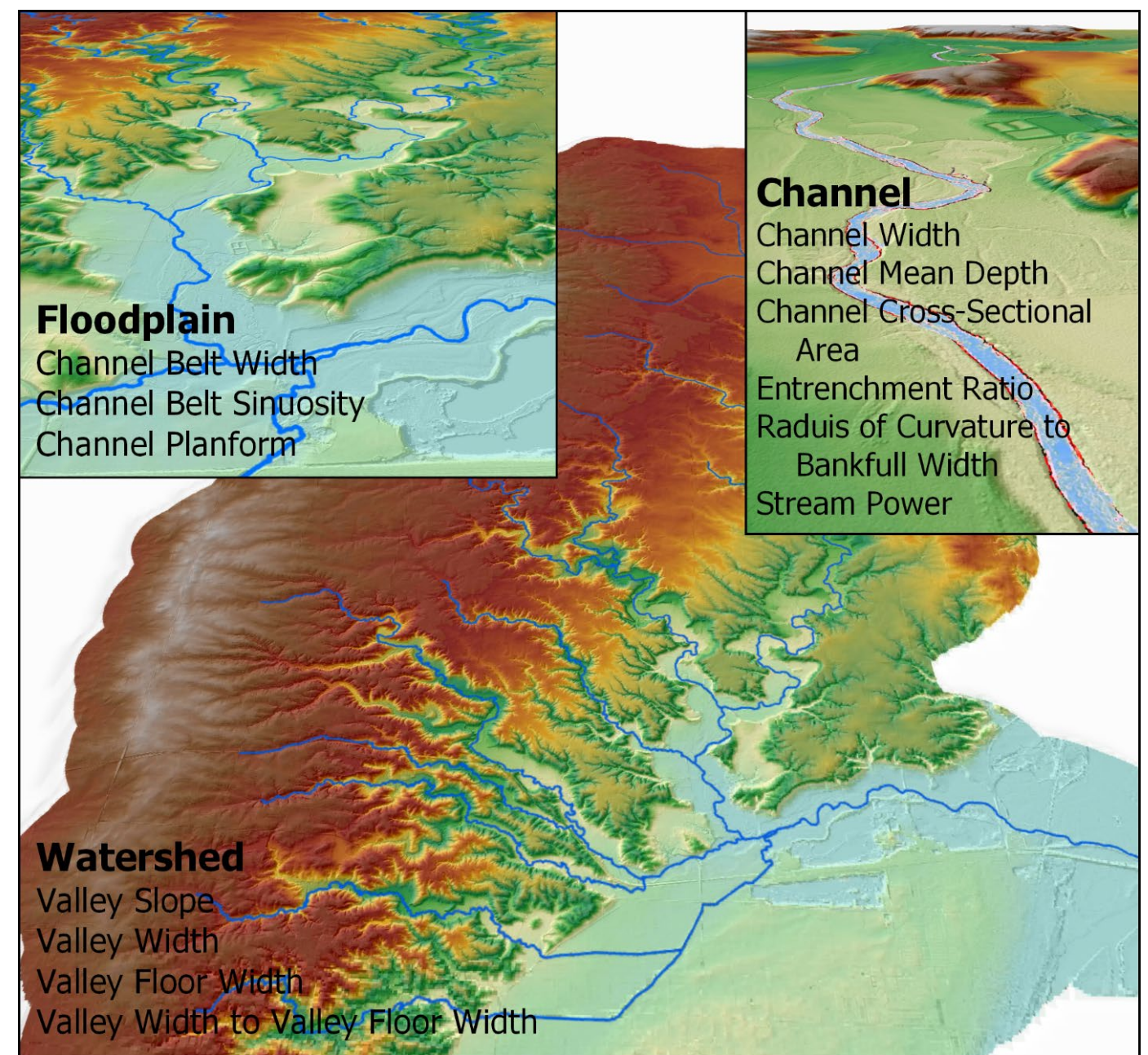

Figure 1. Watershed analysis workflow.

REGIONAL CURVE DEVELOPMENT: Stream systems develop a regular progression of channel form and morphology that naturally balance watershed inputs. Channel forming or bankfull HGR develop from balancing and maintaining a quasi-equilibrium state between sediment supply, slope, channel shape, planform, vegetation, and other factors. In a stable stream, bankfull discharge fills the channel to the active floodplain level providing a delineating morphological feature defining channel forming discharge, sediment transport processes, and depositional features on a floodplain (Dunne and Leopold 1978; FISRWG 1998). Information about bankfull channel geometry and discharge is important to researchers, federal, state, and local governments, and private organizations involved in construction of roadways, bridges, infrastructure projects, stream stabilization and restoration projects, and watershed assessments. Over the past 4 decades, stream analysis, research, and design of restoration and stabilization projects have largely focused on using a natural-channel design approach that is reliant on estimates of bankfull channel geometry and discharge.

A common method for analyzing geomorphic channel stability is to evaluate channel dimensions relative to regional curves that relate bankfull channel dimensions and discharge relative to drainage area through linear regression analysis. The resulting regression models provide morphological channel dimensions that directly relate to channel forming discharge, sediment 
transport processes, and depositional channel features. Watershed assessments and stream restoration design techniques suffer from lack of coverage of regional curves for specific hydrophysiographic regions and subregions, which limits the capacity to analyze many ungaged watersheds lacking this data.

LiDAR-HGR based regional curves can be developed by combining existing and discontinued stream gage data, rating curves, and datum conversions with high-resolution terrain data to capture natural geomorphic channel characteristics (Haring et al. 2019). Standard regional curve development is based on traditional geomorphic field surveys capturing bankfull channel dimensions at stable riffle or channel cross-over locations. The LiDAR-HGR methodology also assembles riffle data surveys that provide the least amount of bankfull mean depth error. Similarly, LiDAR-HGR requires an adequate number of gages within a hydro-physiographic region of interest to effectively capture the variation of fluvial geomorphic bankfull conditions. Once the LiDAR-HGR regional curves are assembled, departure analysis comparing channel dimensions from the existing ungaged watershed to the LiDAR-HGR regional curve can be completed. If the channel dimensions at the ungaged watershed location are within the $90 \%$ confidence interval, then the channel is considered to be stable. If the channel dimensions fall outside the $90 \%$ range, then further analysis is required from other channel and planform matrices. The process for constructing a regional curve is depicted in the flow diagram below (Figure 2).

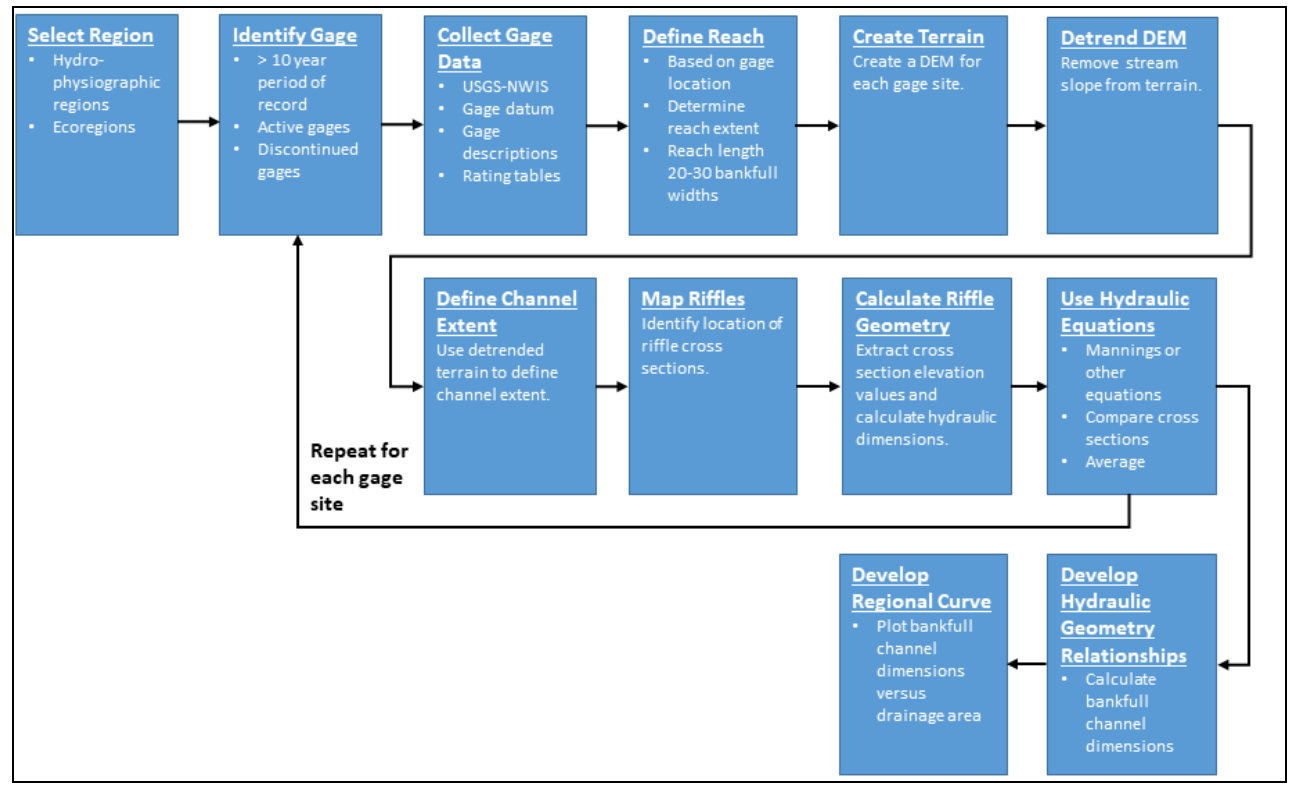

Figure 2. LiDAR-HGR regional curve workflow.

CHANNEL METRICS: This study incorporates open source geospatial tools to support channel, floodplain, valley, and watershed geomorphic analysis. Traditional geomorphic field-based data collection methods, out of necessity, gather and measure channel dimensions and slope using well-established ground survey methods (Harrelson et al. 1994). The traditional field surveys are often limited with constraints on time, funding, and the availability of appropriate survey personnel. In addition, recent literature regarding stream restoration indicates that traditional field survey methods for gathering bankfull channel dimensions may be error prone with reported errors ranging from 5\% to 25\% (Hammer 1981; Wahl 1977). Conversely, this rapid 
watershed assessment method uses existing high-resolution spatial data that can greatly increase the spatial extent and precision of stream assessments thereby reducing time and cost.

An ArcGIS fluvial geomorphology toolbox was developed exclusively for this study to process high-resolution terrain data, extract channel dimensions, and use existing empirical relationships to provide rapid watershed analysis. The toolbox and resulting channel metrics are all based on the concept of bankfull discharge and its effectiveness in shaping the dimension, pattern, and profile of the channel, floodplain, valley, and watershed. Dunne and Leopold (1978) are credited with the commonly accepted and universally applicable definition of bankfull discharge as "the bankfull stage corresponding to the discharge in which the channel maintenance is most effective, that is, the discharge that is moving sediment, forming or removing bars, forming or changing bends and meanders, and generally doing work that result in the average morphological characteristics of channels." The bankfull discharge and associated channel dimensions are the defining analysis tools that quantify channel metrics relative to empirical relationships known to support stable, intermediate, or unstable stream channel conditions. For example, the sinuosity metric is measured by stream length divided by valley length, and values less than 1.2 may indicate channelization, coupled with a width-to-depth ratio of less than 10 may indicate channel instability in the form of channel bed degradation.

The stream channel metrics are described in Table 1 and are based on bankfull channel dimensions to include width, mean depth, cross-sectional area, discharge, water surface slope, width-to-depth ratios, entrenchment ratios, sinuosity, radius-of-curvature, stream power, and additional planform matrices.

\begin{tabular}{|c|c|}
\hline \multicolumn{2}{|c|}{$\begin{array}{l}\text { Channel Dimension } \\
\end{array}$} \\
\hline $\begin{array}{l}\text { Width, Mean Depth, } \\
\text { Cross-sectional Area }\end{array}$ & $\begin{array}{l}\text { Required for Regional Curve Development: Dimensions of bankfull width } \\
\text { (ft) and mean depth (ft), cross-sectional area, and discharge (cfs). These } \\
\text { are typically plotted against drainage area (square miles). }\end{array}$ \\
\hline Width to Depth Ratio & $\begin{array}{l}\text { Shape of the channel based at bankfull width (ft) and mean depth (ft) at } \\
\text { bankfull discharge. }\end{array}$ \\
\hline Entrenchment Ratio & $\begin{array}{l}\text { Depicts relative access to the active floodplain. Typically, at two times the } \\
\text { maximum bankfull depth, the water surface width should be at least two and } \\
\text { one-half times the water surface width at bankfull depth. This ratio may be } \\
\text { less depending on channel boundary materials and resistance to erosion. }\end{array}$ \\
\hline \multicolumn{2}{|r|}{ Planform Geometry } \\
\hline Sinuosity & $\begin{array}{l}\text { Sinuosity is the ratio of stream length to valley length. It can also be } \\
\text { described as the ratio of valley slope to channel slope for defined reaches. } \\
\text { Less than } 1.2 \text { likely means a channelized reach and combined with the } \\
\text { width-to-depth ratio less than } 10 \text { may indicate incised channel reaches. }\end{array}$ \\
\hline $\begin{array}{l}\text { Radius of } \\
\text { Curvature(Rc)/ } \\
\text { Bankfull Width }\end{array}$ & 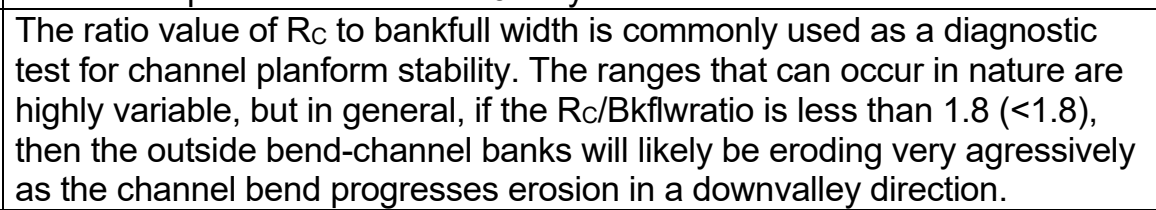 \\
\hline \multicolumn{2}{|r|}{ Energy } \\
\hline Stream Power $(\mathrm{S} \times \mathrm{Q})$ & $\begin{array}{l}\text { Stream Power is the slope }(S) \times \text { discharge }(Q) \\
Q_{s} Q_{50} \sim S Q ; \text { Lanes-Balance of Dynamic River Forces }\end{array}$ \\
\hline
\end{tabular}


FLUVIALGEOMORPH TOOLBOX: The FluvialGeomorph toolbox is designed to provide a comprehensive set of tools for transforming raw terrain data into a set of synthetically derived stream characteristics to derive common fluvial geomorphic metrics (Table 1). The toolbox contains purpose-built Python tools (Table 2) designed to run within ESRI ArcGIS Desktop or ArcPro (ESRI, 2018) to perform geospatial analysis. Some of these Python tools call custom R (R Core Team 2018) functions to perform statistical analysis and graphing. This modular design allows flexibility to support both geospatial analysis and automated report generation. TauDEM (Tarboton 2018) is used for many of the hydro-modification steps. This toolbox was heavily influenced by the currently inactive and closed-source River Bathymetry Toolkit (McKean et al. 2009).

\begin{tabular}{|l|l||}
\hline \multicolumn{2}{|l||}{ Table 2. FluvialGeomorph tools. } \\
\hline Tool & Description \\
\hline Burn Cutlines & Burns cutlines into DEM* to ensure water flows across terrain \\
\hline Contributing Area & Calculates the up-slope area for each DEM pixel \\
\hline Stream Network & Develops synthetic stream network from hydromodified DEM \\
\hline Gradient & Calculates stream slope and sinuosity \\
\hline Create Flowline & Constructs a smooth flowline route \\
\hline Stream Profile Points & Converts flowline to points and calculates elevation \\
\hline Detrend DEM & Creates a DEM with valley slope removed \\
\hline Channel Extent & Creates a channel extent polygon \\
\hline Channel Slope & Calculates a channel extent slope raster \\
\hline Centerline & Creates a centerline from channel extent \\
\hline XS Layout & Creates a set of regularly spaced cross sections \\
\hline XS Watershed Area & Calculates drainage area for each cross section \\
\hline XS Assign River Position & Calculates the longitudinal position of each cross section \\
\hline XS Create Station Points & Converts cross sections to points and calculates elevation \\
\hline XS Dimensions & Calculates cross section hydraulic dimensions \\
\hline Reach Bankfull Graph & $\begin{array}{l}\text { Graphs sensitivity analysis results for a specified bankfull elevation } \\
\text { for selected regions }\end{array}$ \\
\hline Reach Geometry Graph & $\begin{array}{l}\text { Graphs the hydraulic geometry dimensions for a specified bankfull } \\
\text { elevation }\end{array}$ \\
\hline XS Plot & Graphs a single cross section for a specified bankfull elevation \\
\hline${ }^{*}$ DEM = digital elevation model & \multicolumn{2}{|l||}{} \\
\hline
\end{tabular}

FluvialGeomorph tools must be organized into a series of ordered steps, which are referred to as workflows. This project has so far developed two workflows: rapid watershed assessment and regional curve development. For example, Figure 3 is a flow model of the individual steps for the Watershed Analysis workflow described in Table 2. Within each workflow step, one or more FluvialGeomorph tools may be required to accomplish that step. The modular design of the FluvialGeomorph toolbox allows new tools to be created to support a new tasks, modify existing workflows, and move to new watersheds. 


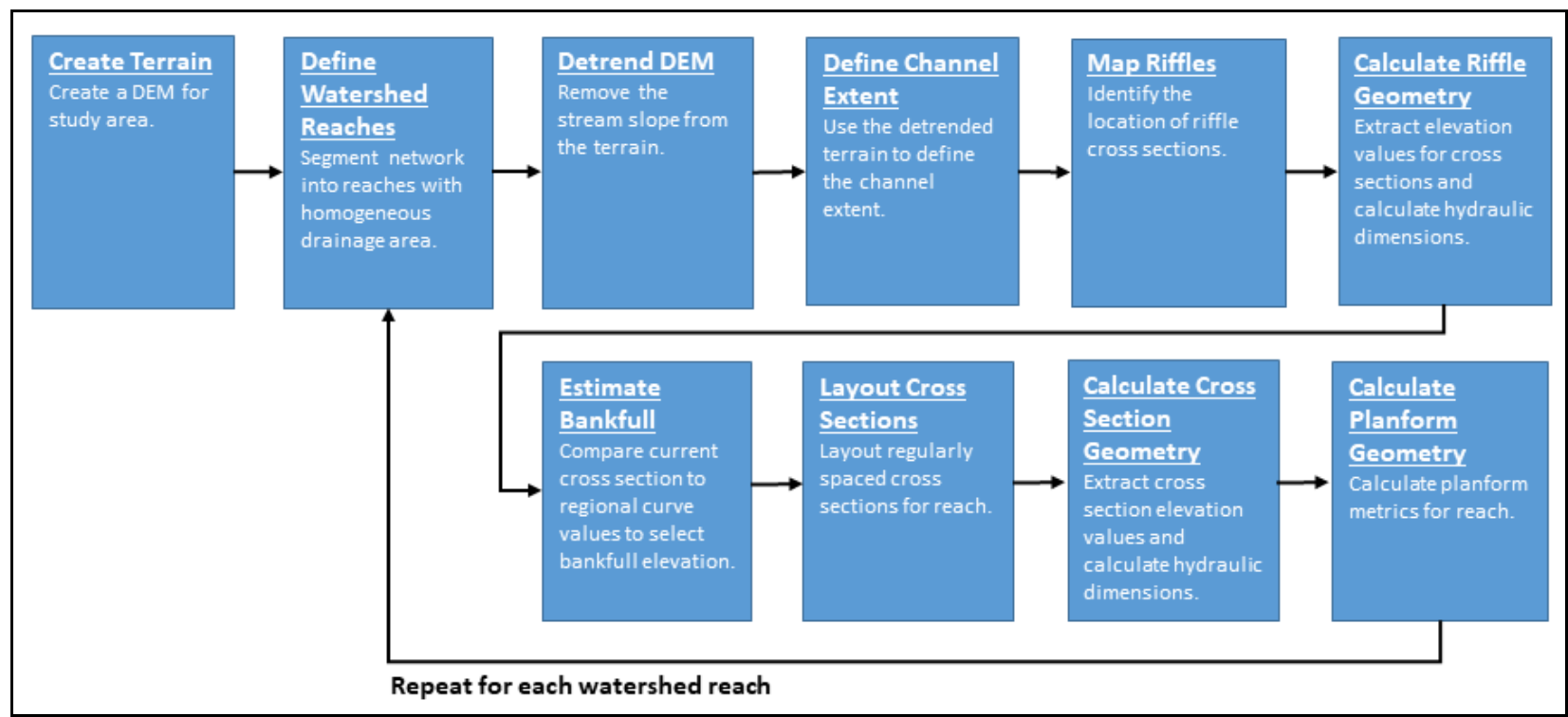

Figure 3. Watershed analysis workflow.

STREAM HABITAT RELATIONSHIPS: Given the fidelity of LiDAR-derived stream metrics described in this study, these stream characteristics should serve as strong predictors of aquatic habitat. To make the link between terrain-derived stream characteristics and the quality of aquatic habitat, this study will use stream metrics as predictor variables of aquatic health measured by such metrics as Index of Biological Integrity (IBI) scores. Machine learning methods will be used to train and test this habitat response model in Minnesota River Basin streams to demonstrate that the watershed, valley, floodplain, and channel metrics can predict fish community characteristics. A subset of available fish sample sites to characterize the Minnesota River Basin across several physiographic regions will be selected. The correlations can be validated against remaining sites to define relationships for extrapolation throughout the basin.

If stream metrics prove to be good predictors of IBI scores for the existing condition, then Future Without Project and project alternatives can be analyzed for habitat impacts using this model. This approach makes the most use of existing LiDAR and state-level IBI data, making it feasible in a rapid assessment framework.

\section{CONCLUSION: HOW DOES THIS HELP THE USACE PLANNING PROCESS?}

Developing habitat relationships is important for USACE Ecosystem Restoration planning and watershed analysis, and this project provides an efficient rapid watershed assessment methodology. Integrating channel, floodplain, valley, and watershed-wide remote sensing data analysis with existing biological data is more efficient relative to quantitative hydrologic models and can provide high-resolution information during the earliest steps of watershed planning. For this project, existing Minnesota River biological data are used to estimate fisheries potential and to evaluate alternative management plans.

The rapid watershed assessment approach integrates channel metrics and biological data to identify potential benefits of stream restoration alternatives and downstream habitats impacted by excessive sedimentation. The analysis approach uses existing regional curves or develops new curves based on the LiDAR-HGR methodology to analyze geomorphic channel metrics that detect channel stability issues identifying watershed-wide locations (Haring et al. 2019). Once 
unstable channel locations or reaches are identified, cumulative steps toward alternative restoration plans and project completion could be conceived and quantitatively evaluated for sediment retention potential and habitat analysis.

The rapid watershed assessment provides efficiency desired for modern USACE district planners and may also be used for disaster and hazard assessment in fire-damaged landscapes. While designed for watershed habitat restoration assessment, the watershed assessments may be used to support regulatory cumulative effects analysis. In conditions where main-stem river backwater sedimentation issues exist or navigation channel dredging is impacted, potential sources and locations of sediment delivery from the watershed can be provided based on the geomorphic watershed analysis. Once the potential sediment sources are located in the tributary streams, then focused watershed and habitat restoration projects can be investigated and implemented.

The approach provides a relatively quick, thorough, geomorphic-based, watershed-wide assessment capability that has not been provided elsewhere, based on current information. This is particularly useful for watersheds that lack biological data to support habitat evaluations as is common in most project sites. The integration of the rapid watershed assessment and biological data will produce a plan that compiles results into a habitat benefits model for nationwide application. The analysis method provides the ability to produce high-resolution, quantitative geomorphic assessments over large spatial ranges.

ADDITIONAL INFORMATION: This Coastal and Engineering Technical Note (CHETN) was prepared as part of the Ecosystem Management and Restoration Research Program (EMRRP) and was written by Christopher P. Haring (Christopher.P.Haring@usace.army.mil) of the US Army Engineer Research and Development Center, Coastal and Hydraulics Laboratory; Charles H. Theiling (Charles.H.Theiling@usace.army.mil) of the ERDC, Environmental Laboratory; and Michael P. Dougherty (Michael.P.Dougherty@usace.army.mil) of USACE, Rock Island District. Business Line Manager for the Civil Works Environmental Business Line is Mindy Simmons; Technical Director for Civil Works, Environmental Engineering and Sciences is Al Cofrancesco; and the EMRRP Program Manager is Trudy Estes. This CHETN should be cited as follows:

Haring, C. H., C. H. Theiling, and M. P. Dougherty 2018. Rapid Watershed Assessment Planning Tools Based on High-Resolution Terrain Analysis. ERDC/CHL CHETN-VII-22. Vicksburg, MS: US Army Engineer Research and Development Center. http://dx.doi.org/10.21079/11681/36714

\section{REFERENCES}

Dunne, T., and L. B. Leopold. 1978. Water in Environmental Planning. San Francisco, CA: W. H. Freeman and Co.

ESRI 2018. ArcGIS Desktop (version 10.5.1). Redlands, CA: Environmental Systems Research Institute.

FISRWG (Federal Interagency Stream Restoration Working Group). 1998 (Revised August 2001). Stream Corridor Restoration: Principles, Processes and Practices. National Technical Information Service. Springfield, VA: US Department of Commerce.

Hammer, R. G. 1981. Streamflow Estimates Using Channel Width: Missoula, Mont. US Forest Service, Northern Region, Soil, Air, and Water Notes 81-3. 
Haring, C. H., F. H. Weirich, B. D. Cramer, J. A. Dorale, T. C. Foster, and L. J. Weber. 2019. An Assessment of a LiDAR-based Approach for Estimating Hydraulic Geometry Regional and Regime Relationship Curves for the Southern Driftless Area of the Midwest.

Harrelson, C. C., C. L. Rawlins, and J. P. Potyondy. 1994. Stream Channel Reference Sites: An Illustrated Guide to Field Technique. Gen. Tech. Rep. RM-245. Fort Collins, CO: US Department of Agriculture, Forest Service, Rocky Mountain Forest and Range Experiment Station.

McKean, J., D. Nagel, D. Tonina, P. Bailey, C. W. Wright, C. Bohn, and A. Nayegandhi. 2009. "Remote Sensing of Channels and Riparian Zones with a Narrow-Beam Quatic-Terrestrial LiDAR." Remote Sensing 1: 1065-1096; doi:10.3390/rs1041065

R Core Team 2018. R: A Language and Environment for Statistical Computing (version 3.5.1). Vienna, Austria: R Foundation for Statistical Computing. https://www.R-project.org

Tarboton, David. 2018. Terrain Analysis Using Digital Elevation Models (TauDEM, version 5.3.7). Logan, UT: Utah State University. http://hydrology.usu.edu/taudem/taudem5/

Thorp, J. H., M. C. Thoms, and M. D. Delong. 2006. “The Riverine Ecosystem Synthesis: Biocomplexity in Riversystems across Space and Time." River Research and Applications 22: 123-147.

USACE (US Army Corps of Engineers). 2000. Planning Guidance Notebook. Engineer Regulation 1105-2-100. U.S. Army Corps of Engineers, Washington, DC.

Wahl, K. L. 1977. “Accuracy of Channel Measurements and Implications in Estimating Streamflow Characteristics." US Geological Survey Journal of Research 5(6): 811-814.

Water Resources Development Act of 2007. Public Law 110-114, 121 STAT. 104, Nov. 8, 20071. US 110th Congress 33 USC 2201. https://www.congress.gov/110/plaws/publ114/PLAW-110publ114.pdf

Williams, B. S., E. D'Amico, J. H. Kastens, J. H. thorp, J. E. Flotemersch, and M. Thoms. 2013. “Automated Rivering Landscape Characterization: GIS-Based Tools for Watershed-Scale Research, Assessment, and Management." Environmental Monitoring and Assessment 185: 7485-7499.

NOTE: The contents of this technical note are not to be used for advertising, publication,

or promotional purposes. Citation of trade names does not constitute an official endorsement or approval of the use of such products. 